\title{
Seismic elastic-plastic time history analysis and reliability study of quayside container crane*
}

\author{
Yulong $\mathrm{Jin}^{*}$ and Zengguang Li \\ State Key Laboratory of Mechanical System and Vibration, Shanghai Jiao Tong University, Shanghai 200240, China
}

\begin{abstract}
Quayside container crane is a kind of huge dimension steel structure, which is the major equipment used for handling container at modern ports. With the aim to validate the safety and reliability of the crane under seismic loads, besides conventional analysis, elastic-plastic time history analysis under rare seismic intensity is carried out. An ideal finite element (FEM) elastic-plastic mechanical model of the quayside container crane is presented by using ANSYS codes. Furthermore, according to elastic-plastic time history analysis theory, deformation, stress and damage pattern of the structure under rare seismic intensity are investigated. Based on the above analysis, the established reliability model according to the reliability theory, together with seismic reliability analysis based on Monte-Carlo simulation is applied to practical analysis. The results show that the overall structure of the quayside container crane is generally unstable under rare seismic intensity, and the structure needs to be reinforced.
\end{abstract}

Key words: quayside container crane; elastic-plastic time history analysis; seismic reliability; elastic-plastic beam element; earthquake action

CLC number: P315.97 Document code: A

\section{Introduction}

Quayside container crane is a main equipment used for handling containers at modern harbors. Higher requirements for operating load and operating speed are proposed due to rapid development trend of large-scale container ships. With increase of structure size of the quayside container crane, dynamic characteristics analysis has become a hotspot. Because of the structure hugeness and complexity, its operation safety becomes more and more important. Currently, the researches related to this kind of huge structure mainly refer to the equipment design with the performance of lowing wind load and seismic load. It is the main part in designing the quayside container crane in China, as an earthquake-prone country, to improve the seismic performance and reduce the damages of super-scale equipments in disasters. Therefore, it is necessary to accurately analyze the elastic-plastic performance of quayside container crane structure under earthquake excitations and consider the material nonlinearity influence (Ren,

\footnotetext{
* Received 15 March 2010; accepted in revised form 7 May 2010; published 10 June 2010.

^ Corresponding author. e-mail: jyl19820525@sjtu.edu.cn

(C) The Seismological Society of China and Springer-Verlag Berlin Heidelberg 2010
}

2007). Jin et al (2009) employed the limited state method to analyze dynamic characteristics of the huge steel structure under basic seismic intensity excitation, and calculated the corresponding reliability. Wu et al (2008) proposed an elastic-plastic time history analysis to study seismic performances of T2 building of Shanghai Pu-Dong International Airport. Lü et al (2005) converted actual seismic records into experiments by using the elastic-plastic time history analysis method. There are lots of similar methods and researches. With the relative research enlightened, the author presented numerical methods which take the rare seismic intensity into account based on typical past earthquake records and analyzed the seismic reliability, trying to effectively identify the precursory anomalies, and provide a new method for application research on dynamic characteristics of quayside containers crane.

In this paper, an ideal elastic-plastic mechanical model of quayside container crane is presented by using the ANSYS codes, and the elastic-plastic time history analysis under the rare seismic intensity is analyzed by taking advantage of El Centro seismic wave, Taft seismic wave and SHW2 seismic wave. On the basis of the above-mentioned analysis, the seismic reliability based on Monte-Carlo numerical simulation of the quayside 
container crane is calculated. According to the analysis result, we could observe the seismic response and the seismic features after entering into plastic deformation. The calculation result not only provides an effective theoretical basis for seismic design of the quayside container crane, but also forms a good foundation for designing damping device.

\section{Analysis model of quayside container crane structure}

\subsection{Component propertiesf the whole structure}

Quayside container crane is composed of operation cart, portal structure (including legs of landside and wa- terside, sill beam of landside and waterside, portal of landside and waterside, horizontal beams and fixed tie links system), boom, girder, drawbar system, operation machine facility, operation trolley and hoisting appliance, as shown in Figure 1. The operation cart moves along the ground tracks in lateral $(O y)$ direction, and the operation trolley moves along the beam tracks in longitudinal $(O x)$ direction, handling containers on the docked ships. The material of quayside container crane is Q345 steel, and the material properties of the FEM model are represented by yield limit $\sigma$, elastic modulus $E$, Poisson's ratio $\mu$, and density $\rho$. Here $\sigma=3.45 \times 10^{8} \mathrm{~Pa}$, $E=2.06 \times 10^{11} \mathrm{~Pa}, \mu=0.3$, and $\rho=7.85 \times 10^{3} \mathrm{~kg} / \mathrm{m}^{3}$.

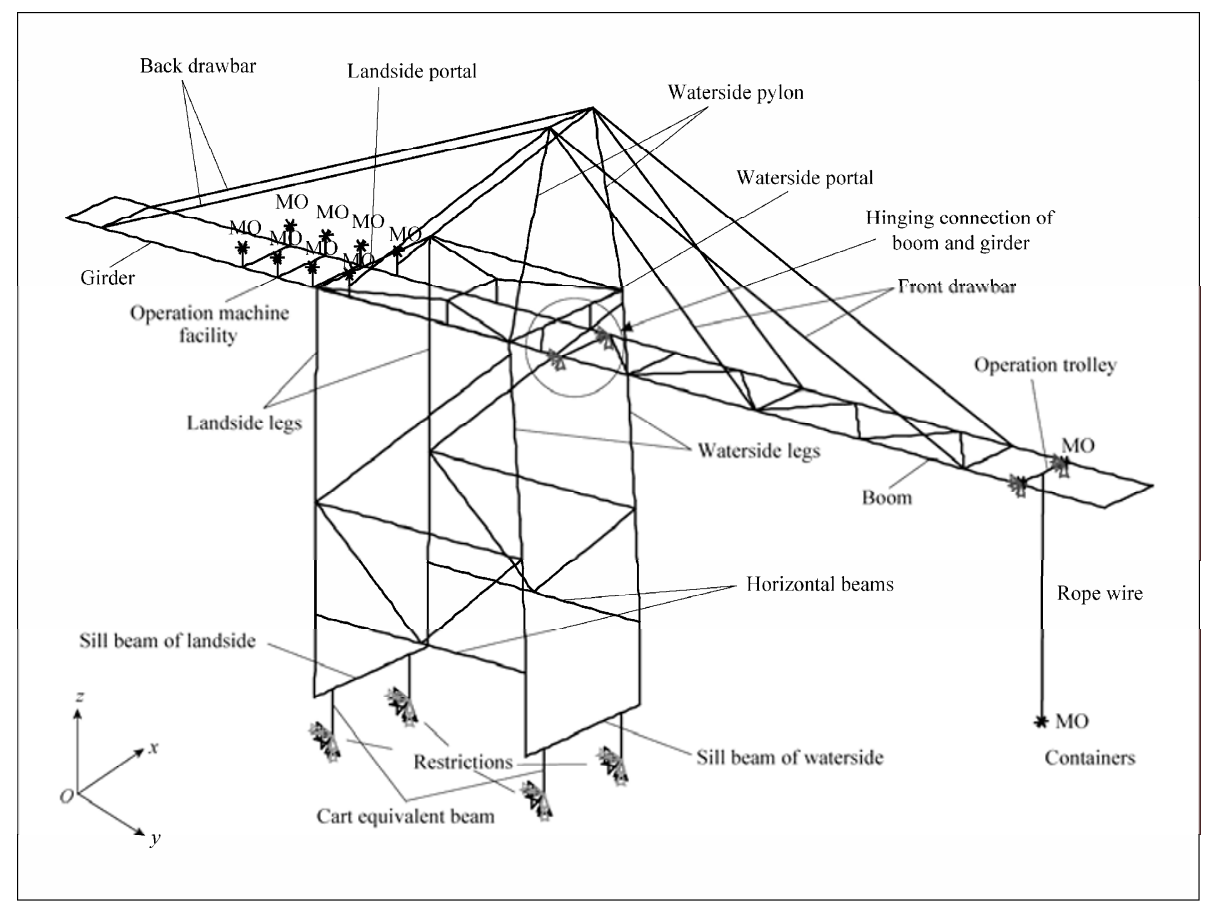

Figure 1 FEM model of quayside container crane.

In this paper, the elastic-plastic elements, such as Beam188 element, Pipe20 element, Mass21 element, Link10 element and Matrix 27 element, are mainly used to analyze the seismic responses. Because the quayside container crane is mainly made of Q345 steel, the constitutive law of material must be considered in the ANSYS analysis. In the course of analysis, the material properties of the elastic-plastic elements are defined as multi-linear kinematic hardening (MKIN), which adopts the Von Mises yield criterion and considers Bauschinger effect. Based on the accurate experiment description of Wang (2006) to Q345 steel, the simplified constitutive law model of material is shown in Figure 2.

\subsection{FEM model of the whole structure}

By using the preprocessor module in ANSYS code, 3D FEM model of the quayside container crane, which is composed of 1420 elements, is built up (Figure 1). The legs of landside and waterside, the sill beam of landside and waterside, the portal of landside and waterside, the horizontal beams, the boom and the girder are all represented by Beam 188 element. The waterside pylon and the portal fixed tie links are represented by Pipe20 element. The operation cart model built up by Beam188 element is simplified as the equivalent beam 


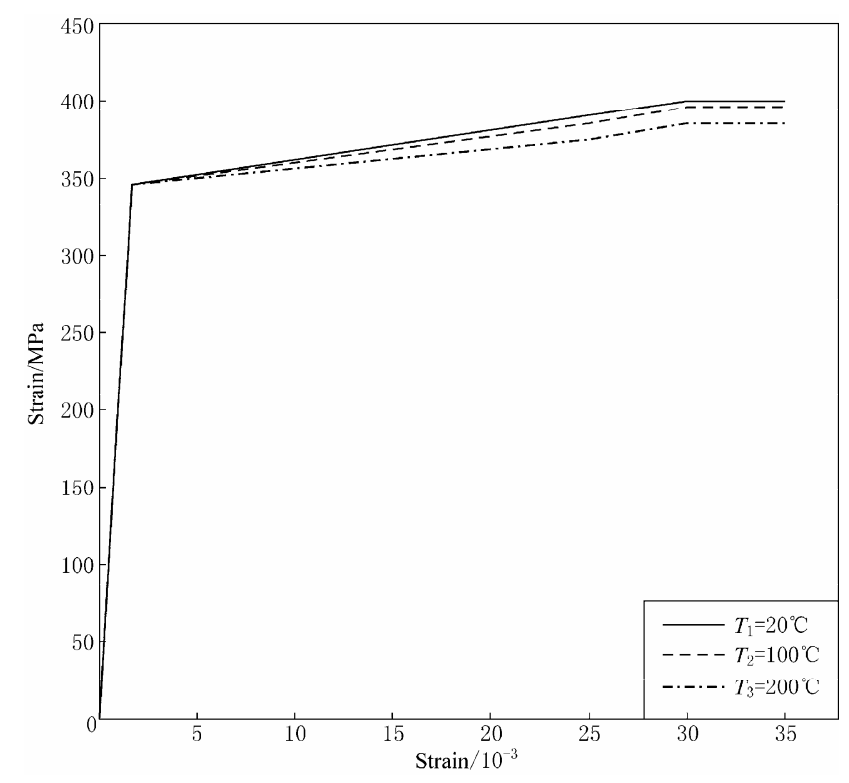

Figure 2 The simplified constitutive law of the model.

in accordance with equivalent stiffness. The operation machine facility, the operation trolley, the hoisting appliance and the containers, which are treated as the concentrated mass, are represented by Mass 21 element. In addition, the linear elements Link10 and Matrix27 are used to represent the drawbar system and the rope wire, respectively. According to actual conditions, the operation machine facility, the operation trolley, the hoisting appliance and the containers are simplified as 6,2,1 and 1 concentrated mass, respectively. The total weight is 1585 tons (Jin et al, 2009).
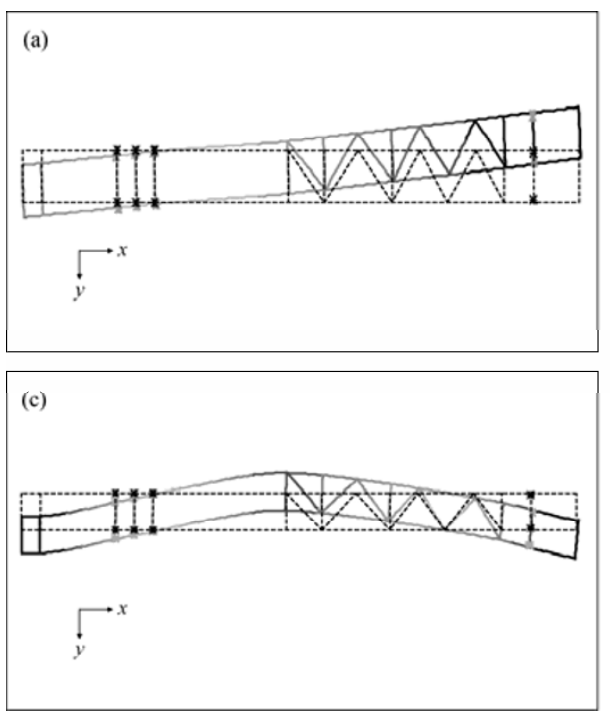

The boom and the girder of quayside container crane are hinged with connecting nodes by the degree of coupling simulation. The bottom of the operation cart is restrained for three translational degrees of freedom and two rotational degrees of freedom around $O x$-axis and $\mathrm{O} z$-axis. Details are shown in Figure 1.

\section{Modal analysis of structure}

Modal analysis is a kind of modern method for studying structure dynamic characteristics, and possesses significant applications in engineering vibration field. Therefore, it is necessary to study the modal analysis to the quayside container crane structure firstly. By using the subspace method in the modal analysis, we get the first 10 natural frequencies and main vibration modal characteristics, as shown in Table 1. Figure 3

Table 1 The first 10 natural frequencies and vibration modal characteristics of the quayside container crane

\begin{tabular}{|c|c|c|}
\hline No. & $\begin{array}{c}\text { Frequency } \\
\quad / \mathrm{Hz}\end{array}$ & Vibration modal characteristics \\
\hline 1 & 0.088 & Lateral pendulum motion of the container \\
\hline 2 & 0.091 & Longitudinal pendulum motion of the container \\
\hline 3 & 0.287 & Torsion of the boom and girder around the portal \\
\hline 4 & 0.372 & Lateral bending of the portal \\
\hline 5 & 0.628 & $\begin{array}{l}\text { Longitudinal bending of the portal and vertical } \\
\text { bending of the girder and boom }\end{array}$ \\
\hline 6 & 0.728 & Vertical bending of the girder and boom \\
\hline 7 & 1.178 & Lateral bending of the girder and boom \\
\hline 8 & 1.504 & The first torsion of the boom \\
\hline 9 & 1.609 & $\begin{array}{l}\text { The second vertical bending of the boom and the } \\
\text { first vertical bending of the girder }\end{array}$ \\
\hline 10 & 1.656 & The second lateral bending of the girder \\
\hline
\end{tabular}
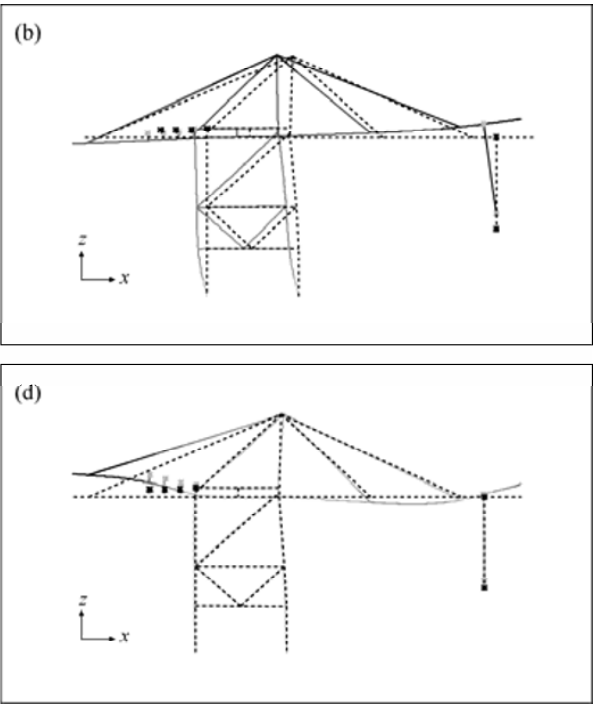

Figure 3 Main vibration modals of the quayside container crane. (a) The third frequency of $0.287 \mathrm{~Hz}$; (b) The fifth frequency of $0.628 \mathrm{~Hz}$; (c) The seventh frequency of $1.178 \mathrm{~Hz}$; (d) The ninth frequency of $1.609 \mathrm{~Hz}$. 
shows four main vibration modals of the quayside container crane. It can be seen from Figure 3 that, when the operation trolley is located at the front-end of the boom and hoisting containers, the third and the seventh modals play a significant role in the lateral earthquake response, whereas the fifth and the ninth modals have a main effect on the vertical earthquake response.

\section{Elastic-plastic time history analysis of the quayside container crane}

\subsection{Selection and input of seismic waves}

Generally, three groups of seismic recordings are applied to structure transient time-history analysis, that is, actual earthquake records of given site, typical past earthquake records and artificial seismic waves. Based on site conditions, typical past earthquake recordings are selected as input (Wang, 2007).

1) El Centro seismic wave, Taft seismic wave and SHW2 seismic wave are selected as earthquake recordings, and corresponding magnitude, site condition and frequency characteristics are shown in Table 2. Figure 4 gives the original east-west earthquake recordings of the three groups of seismic waves. But it should be noted that the ground acceleration amplitude of seismic waves should be adjusted according to different fortification intensities. Based on the seismic specification requirements of port engineering structures, the seismic fortification intensity of quayside container crane is 7 , type II site condition, characteristic period $T=0.3 \mathrm{~s}$, the structure damping ratio is $5 \%$ based on the Code for Design of Steel Structure (Ministry of Construction of the People's Republic of China, 2003). With the aim to accurately analyze elastic-plastic features of the quayside container crane, the seismic response analysis under rare seismic intensities 7 and 8 are carried out, and the corresponding peak acceleration value should be adjusted to $2.2 \mathrm{~m} / \mathrm{s}^{2}$ and $4.0 \mathrm{~m} / \mathrm{s}^{2}$.

2) During time history analysis, the seismic waves are input in three directions, and the input in each direction is based on the non-correlation requirements. For the sake of simplification, we only give the east-west direction (longitudinal direction) seismic waves of three groups of earthquake recordings, as shown in Figure 4. As a matter of fact, the longitudinal earthquake action (the spindle) plays a significant role in the whole structure.

Table 2 Specific characteristics of the three groups of seismic waves

\begin{tabular}{|c|c|c|c|c|c|c|}
\hline Seismic waves & Site condition & $a_{\max } /\left(\mathrm{m} \cdot \mathrm{s}^{-2}\right)$ & $v_{\max } /\left(\mathrm{m} \cdot \mathrm{s}^{-1}\right)$ & $D_{\max } / \mathrm{m}$ & Predominant period/s & Average period $/ \mathrm{s}$ \\
\hline EL Centro (1940-05-18) & II type site & 3.3697 & 0.3502 & 0.1113 & 0.6827 & 0.5403 \\
\hline Taft $(1952-07-21)$ & II type site & 1.8168 & 0.1717 & 0.0623 & 0.3330 & 0.5240 \\
\hline SHW2 (fitting response spectrum) & II type site & 0.3502 & & & 0.3200 & 0.4500 \\
\hline
\end{tabular}
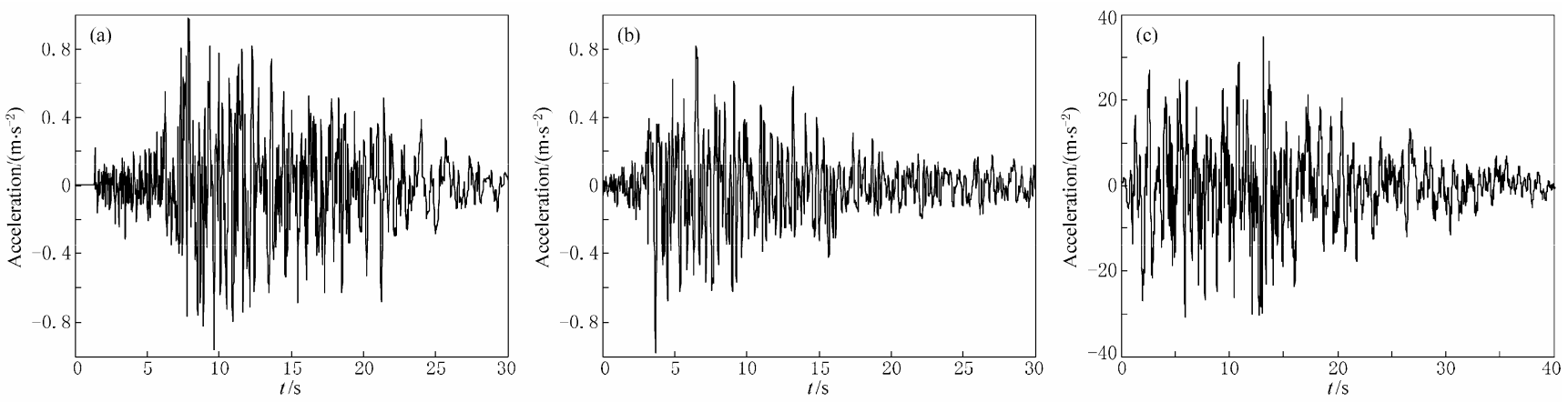

Figure 4 Acceleration time-histories of three seismic waves in north-south direction. (a) El Centro seismic wave; (b) Taft seismic wave; (c) SHW2 seismic wave.

However, with the aim to accurately analyze the most dangerous situation, we adopt the input in three directions. According to seismic design specifications and practical engineering experience, when considering the input in three directions at the same time, the ratio of peak acceleration in longitudinal (east-west) direction, to the peak acceleration in lateral (north-south) direction, and to that in vertical direction, is taken as 1:0.85:0.65.

3) Based on modal analysis results, the natural period of the quayside container crane is around $3 \mathrm{~s}$. According to the time-history theory, the duration time of seismic waves should be as $5-10$ times long as that of 
the natural period. Therefore, the duration time of El Centro, Taft and SHW2 seismic waves are $30 \mathrm{~s}, 30 \mathrm{~s}$ and $40 \mathrm{~s}$, respectively, and the corresponding interval time are all of $0.02 \mathrm{~s}$.

According to seismic design specifications, when using time-history analysis for seismic analysis, the average seismic coefficient curves of the adopted seismic waves and the coefficient curves of the response spectrum method based on vibration modal decomposition must be matched in statistical sense, as shown in Figure 5. From Figure 5 we can see that, although the dynamic amplification factors are different, all of the seismic waves match each other statistically. Therefore, the seismic waves adopted in this study satisfy analytical requirements.

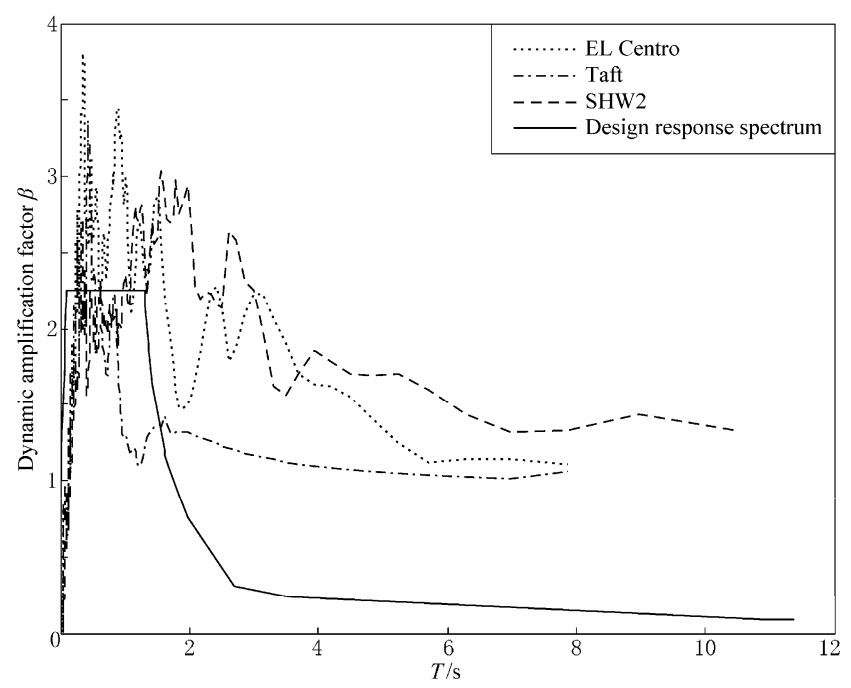

Figure 5 Comparison between the average seismic wave coefficient curves and that of response spectrum.

\subsection{Selection of key nodes and key elements}

The selection of key nodes and key elements of the quayside container crane structure (Jin et al, 2009) is important to the analysis of seismic response. However, it is impossible to give the load effect of each node and each element due to heavy workload. Therefore, only the load effects of key nodes and key elements nearby critical sections of quayside container crane are only given. The concrete positions and the codes of above key nodes and key elements are shown in Table 3.

Table 3 Codes and concrete positions of key nodes and elements of the critical sections

\begin{tabular}{crrl}
\hline Code & Element & Node & Concrete position \\
\hline 1 & 848 & 832 & Back-end of the girder \\
2 & 853 & 833 & Joint of the back drawbar and the girder \\
3 & 878 & 858 & Mass center of the operation machine facility \\
4 & 723 & 333 & Landside portal \\
5 & 744 & 387 & Waterside portal \\
6 & 1018 & 987 & Joint of the front drawbar 1 and the boom \\
7 & 1047 & 1020 & Joint of the front drawbar 2 and the boom \\
8 & 1068 & 1043 & Front-end of the boom \\
9 & 1 & 1 & Joint of horizontal beams and landside legs \\
10 & 89 & 85 & Joint of horizontal beams and waterside legs \\
11 & 1391 & 667 & Joint of the sill beam of landside and cart \\
12 & 1403 & 690 & Joint of the sill beam of waterside and cart \\
\hline
\end{tabular}

\subsection{Results of time-histo ry analysis under rare seismic intensities of 7 and 8}

Table 4 shows the maximum stress and displacement response of critical sections of the quayside container crane under three groups of rare seismic excitations. It can be seen from Table 4 that, (1) under the excitation of rare seismic intensity, the maximum stress is in the joint of horizontal beams and waterside legs, meanwhile, the positions of maximum displacement are nearby the back-end of girder and the front-end of boom;

Table 4 Maximal stress and displacement response of quayside container crane under rare seismic intensities of 7 and 8

\begin{tabular}{|c|c|c|c|c|c|c|c|c|c|c|c|c|}
\hline \multirow{3}{*}{ Concrete position of critical sections } & \multicolumn{4}{|c|}{ EL Centro seismic wave } & \multicolumn{4}{|c|}{ Taft seismic wave } & \multicolumn{4}{|c|}{ SHW2 seismic wave } \\
\hline & \multicolumn{2}{|c|}{$\begin{array}{l}\text { Stress } \\
/ \mathrm{MPa}\end{array}$} & \multicolumn{2}{|c|}{$\begin{array}{l}\text { Displacement } \\
/ \mathrm{mm}\end{array}$} & \multicolumn{2}{|c|}{$\begin{array}{l}\text { Stress } \\
/ \mathrm{MPa}\end{array}$} & \multicolumn{2}{|c|}{$\begin{array}{c}\text { Displacement } \\
/ \mathrm{mm}\end{array}$} & \multicolumn{2}{|c|}{$\begin{array}{l}\text { Stress } \\
/ \mathrm{MPa}\end{array}$} & \multicolumn{2}{|c|}{$\begin{array}{c}\text { Displacement } \\
/ \mathrm{mm}\end{array}$} \\
\hline & 7 & 8 & 7 & 8 & 7 & 8 & 7 & 8 & 7 & 8 & 7 & 8 \\
\hline Back-end of the girder & 6.09 & 10.72 & 236.7 & 441.4 & 2.871 & 5.27 & 135.4 & 214.2 & 8.89 & 14.83 & 453.60 & 809.9 \\
\hline Joint of the back drawbar and the girder & 20.95 & 34.59 & 225.2 & 430.3 & 9.83 & 17.60 & 126.8 & 206.8 & 30.40 & 51.17 & 443.40 & 775.2 \\
\hline Mass center of operation machine facility & 29.68 & 59.88 & 215.1 & 352.9 & 14.09 & 31.38 & 94.7 & 160.6 & 40.02 & 85.02 & 320.30 & 558.5 \\
\hline Landside portal & 37.80 & 71.45 & 198.5 & 314.8 & 17.36 & 35.02 & 88.5 & 142.8 & 58.60 & 114.40 & 267.80 & 472.0 \\
\hline Waterside portal & 48.61 & 94.98 & 169.3 & 266.6 & 22.24 & 45.39 & 75.6 & 129.8 & 69.96 & 132.60 & 219.70 & 364.6 \\
\hline Joint of the front drawbar 1 and the boom & 6.22 & 20.74 & 150.7 & 271.1 & 4.04 & 11.94 & 88.8 & 125.6 & 8.78 & 24.20 & 260.40 & 406.8 \\
\hline Joint of the front drawbar 2 and the boom & 31.05 & 47.90 & 182.3 & 289.1 & 19.52 & 43.11 & 102.3 & 167.2 & 42.78 & 70.68 & 336.00 & 571.6 \\
\hline Front-end of the boom & 4.13 & 4.90 & 211.1 & 312.4 & 3.07 & 3.81 & 125.8 & 212.3 & 8.11 & 13.89 & 426.90 & 720.5 \\
\hline Joint of horizontal beams and landside legs & 119.60 & 334.50 & 106.5 & 191.7 & 62.67 & 120.40 & 55.4 & 98.6 & 113.10 & 366.20 & 99.59 & 175.0 \\
\hline Joint of horizontal beams and waterside legs & 127.10 & 384.80 & 106.6 & 191.7 & 66.67 & 121.20 & 55.4 & 98.7 & 122.40 & 371.40 & 98.85 & 175.2 \\
\hline Joint of the sill beam of landside and cart & 60.58 & 110.20 & 46.9 & 85.3 & 46.80 & 83.48 & 24.5 & 43.7 & 97.28 & 173.40 & 42.28 & 75.3 \\
\hline Joint of the sill beam of waterside and cart & 99.77 & 181.30 & 47.7 & 86.1 & 46.36 & 82.65 & 24.7 & 44.1 & 98.60 & 175.80 & 42.54 & 75.8 \\
\hline
\end{tabular}

Note: Stress and displacement stand for the maximum value of critical sections. 7 and 8 represent rare seismic intensity. 
(2) under SHW2 excitation of rare seismic intensity of 8 , the deformations of the back-end of girder are very large, obviously exceeding stiffness requirements (sag-span ratio $1 / 750$ ). Strong earthquakes could make geometric nonlinearity of the structure enhanced, which leads to large deformation; (3) under the excitation of rare seismic intensity of 7 , the maximum stress of each component of the quayside container crane is at low level, without producing plastic deformation. Nevertheless, under El Centro and SHW2 excitations of the rare seismic intensity of 8 , the stress in the joint of horizontal beams and waterside legs is beyond the limited stress $345 \mathrm{MPa}$, inducing plastic deformation; (4) the responses of the same component show significant large differences under the different seismic waves with the same intensity and standard. It can be found that different seismic waves have great effects on the structure responses. Therefore, it is necessary to choose different seismic waves for time-history analysis of the structure.

In conclusion, there is no need to consider the influence of the material plasticity under three groups of seismic waves of the rare seismic intensity of 7 . However, under rare seismic intensity of 8 , the seismic response of quayside container crane is large enough to induce the plastic deformation. Therefore, the whole structure must be seismically reinforced.

Figure 6 shows the stress time-history curves of the joint of horizontal beams and waterside legs (element 89) under rare seismic intensities of 7 and 8 , and also shows the displacement time history. It can be seen that: (1) the stress variation trend of the joint of horizontal beams and waterside legs (element 89) under rare seismic intensities of 7 and 8 is the same; (2) the largest lateral displacement is located in the back of the girder (node 832). This is because the corresponding frequencies of predominating vibration modals (the seventh and ninth modals) are close to the resonance frequency of seismic waves. By comparison, we can find that the seventh modal has the largest effect on lateral seismic response of quayside container crane; (3) the occurrence time of peak stress and displacement, compared with the entire duration time of seismic waves, shows the characteristics of early occurring. It can be found that the massive shocks of the initial stage of the seismic waves could take an important effect on withstanding the strong earthquakes.
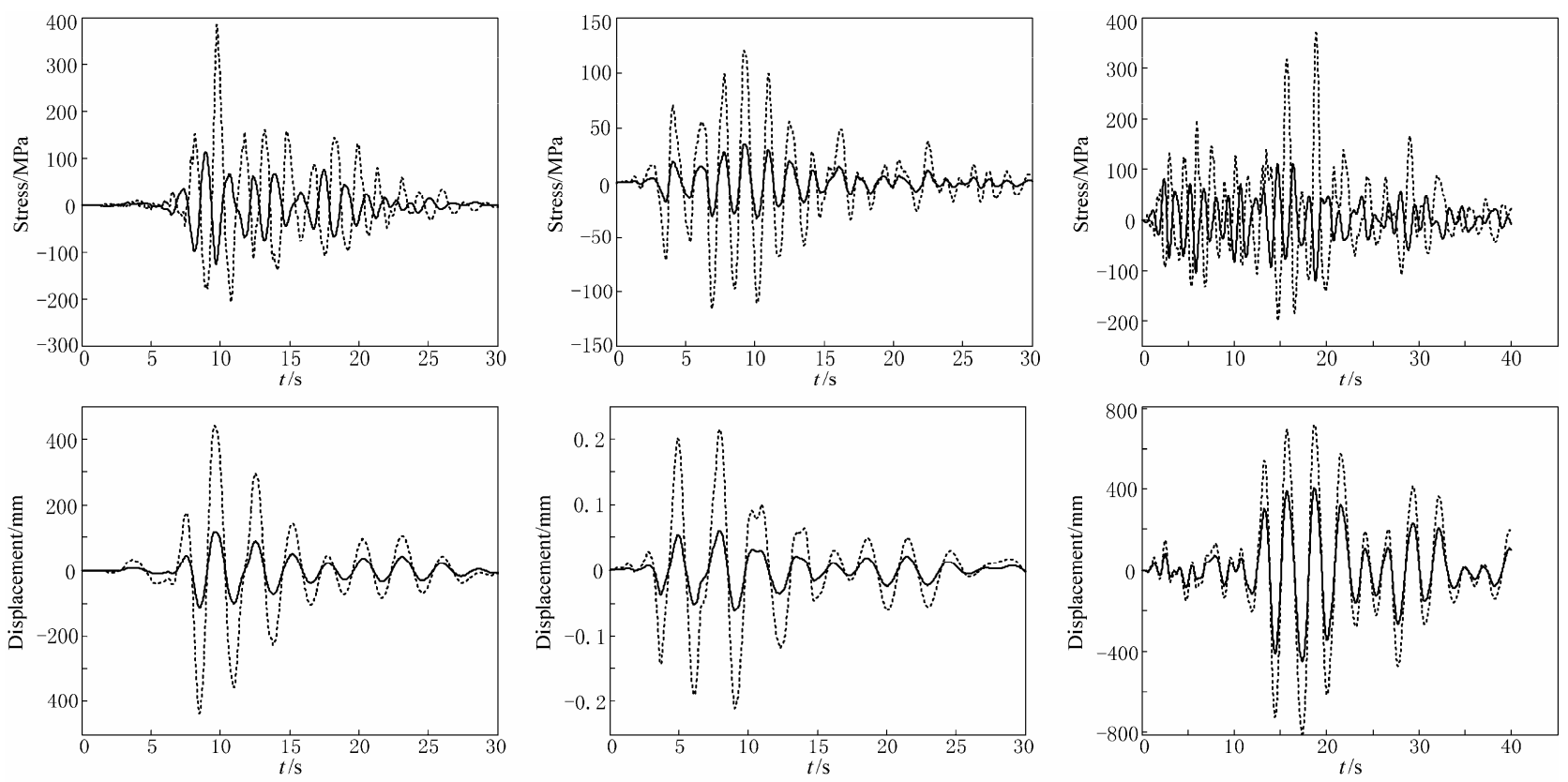

(a)

(b)

Rare seismic intensity 7

........... Rare seismic intensity 8

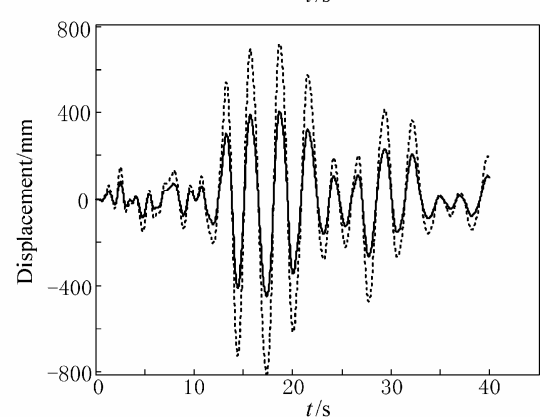

(c)

Figure 6 Time history curves of key nodes and elements under rare seismic intensities of 7 and 8. (a) El Centro seismic wave; (b) Taft seismic wave; (c) SHW2 seismic wave.

The stress and displacement response diagrams of the quayside container crane under the excitation of rare seismic intensity of 8 are shown in Figure 7. It can be clearly seen from Figure 7 the accurate location and appearing time of plastic deformation.

In conclusion, the maximum stress of the quayside 
container crane under rare seismic intensity is 384.8 $\mathrm{MPa}$, which is beyond the limited stress $345 \mathrm{MPa}$. The seismic response of the whole structure is large enough
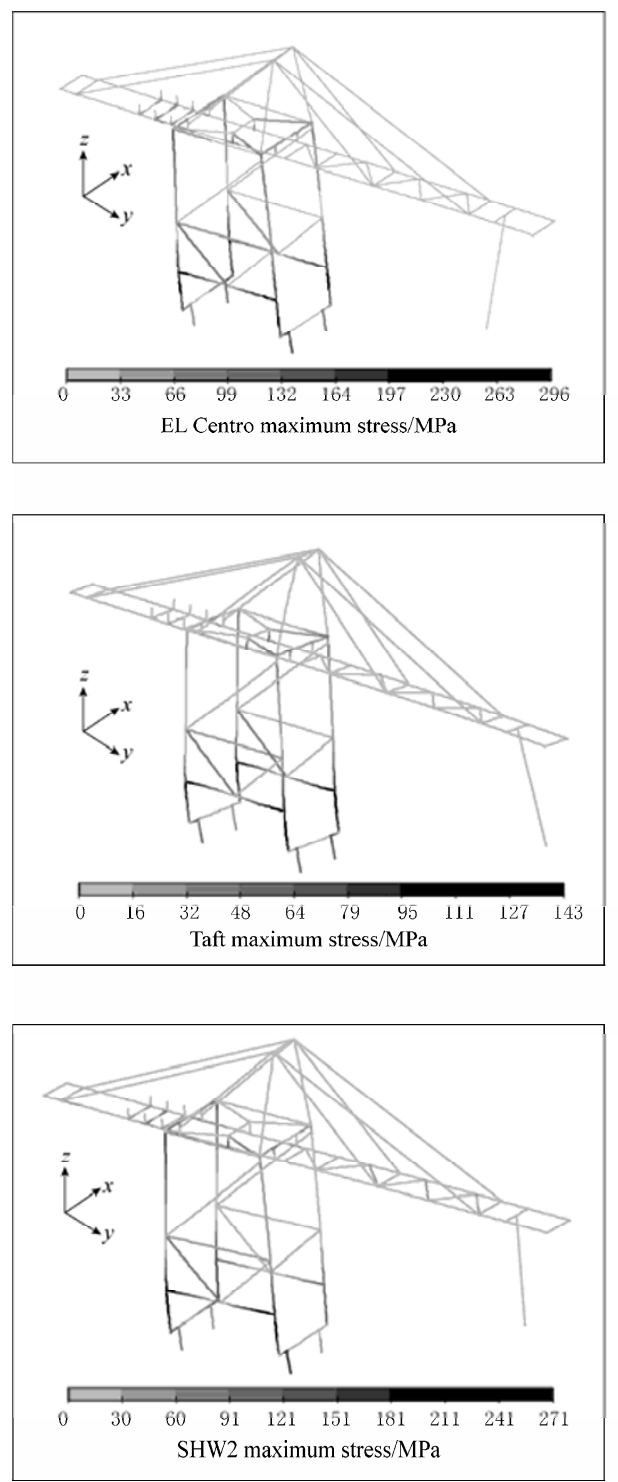

to fall short of the seismic design requirements. Therefore, it is necessary to carry on seismic reliability analysis under rare seismic excitations.
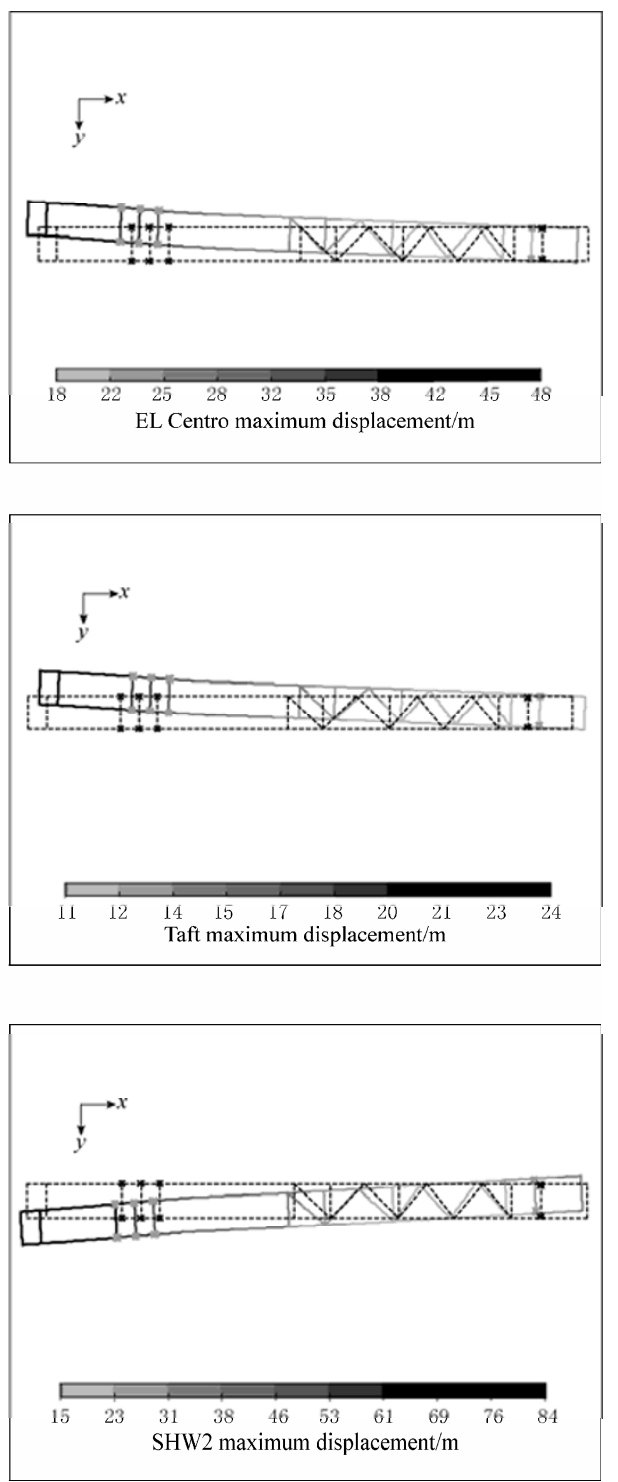

Figure 7 Maximal stress (left) and displacement (right) of quayside container crane under rare seismic intensity of 8.

\section{Seismic performance of the quayside container crane}

\subsection{Related theory on reliability}

The structure reliability refers to the probability that could realize its pre-specified function within the prescribed time and conditions. In general, there are two factors affecting the structure reliability, named loading effect $S$ and resisting force $R$ of the structure component. Here (Ou et al, 1994),

$$
Z=g(R, S)=R-S .
$$

Since both $S$ and $R$ are random variables, $Z$ is also a random variable, which may appear in three kinds of conditions as follows: $Z>0$ (structure is reliable), $Z<0$ (structure failure), and $Z=0$ (the limited state). Here, equation (2) is called the limited state equation,

$$
Z=R-S=0 \text {. }
$$

According to the reliability theory, the structure reliability actually solves the probability of limited state function $Z \geq 0$. Therefore, taking advantage of the prob- 
ability design function (PDF) of the ANSYS codes, the probability of the limited state function $Z \geq 0$ can be calculated.

\subsection{Reliability index and failure probability}

The structure failure probability refers to the probability that could not realize its pre-specified function within the prescribed time and conditions, that is, the probability of the limited state function $Z<0$. The expression is shown as follows:

$$
P_{\mathrm{f}}=p(Z<0)=\int_{r-s} f_{R}(r) f_{S}(s) \mathrm{d} r \mathrm{~d} s,
$$

where $f_{R}(r)$ and $f_{S}(s)$ are the probability density function of the random variable $R$ and $S$, respectively.

The structure reliability index $\beta$ is defined as

$$
\beta=\frac{\mu_{Z}}{\sigma_{Z}},
$$

where $\mu_{z}$ and $\sigma_{z}$ are the mean and standard deviation of the limited state equation $Z=0$, respectively. According to the first-order second-moment method (FOSM) theory, the relationship between structure failure reliability $p_{\mathrm{f}}$ and the structure reliability index $\beta$ is approximated as

$$
P_{\mathrm{f}}=1-\Phi(\beta),
$$

where $\Phi(\beta)$ is standard normal distribution function.

\subsection{Limited state equation of load-carrying ability of the quayside container crane}

The limited state equation of load-carrying ability of the quayside container crane is defined as

$$
Z=\frac{\sigma_{s}}{r_{\mathrm{RE}}}-\sigma_{\max },
$$

where, $\sigma_{s}$ and $r_{\mathrm{RE}}$ stand for structure resisting force and seismic adjustment coefficient, respectively. They are selected as $\sigma_{s}=345 \mathrm{MPa}$ and $r_{\mathrm{RE}}=1.10 . \sigma_{\max }$ is the maximum loading effect, which could be calculated with ANSYS. Since the structure is mainly simulated by beam element, its maximum stress $\sigma_{\max }$ is the absolute value of the sum of normal stress caused by bending deflection on beam section and axial stress.

\subsection{Fitting the data with ground acceleration dis- tribution}

According to the description (Ou et al, 1994) on the distribution type of ground acceleration, the ground acceleration approximately complies with the extreme value of type I distribution. However, there is no corresponding distribution function in ANSYS codes. Therefore, we obtain the extreme value of type I distribution curves through fitting acceleration with several standard normal distribution curves, which are shown in Figure 8.
It can be observed from Figure 8 that the fitted curves are approximately consistent with the initial curves. The means of seismic waves after fitting as the normal distribution curves are $-0.14570,-0.04980$ and -0.03708 , respectively, and the corresponding standard deviations are $1.03409,0.76229$ and 0.543157 , respectively. Similarly, the probability density function curves of the lateral and vertical seismic waves can also be fitted based on the above regularity.

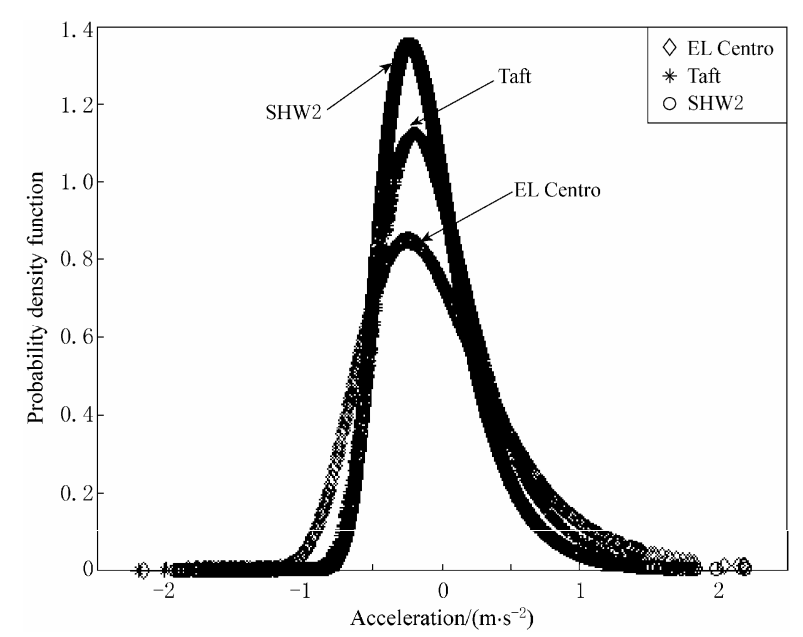

Figure 8 Normal distribution curves from fitting longitudinal acceleration of three groups of seismic waves.

According to the statistics of the Code for Design of Steel Structure (Ministry of Construction of the People's Republic of China, 2003) on Q345 steel, the ratio of the mean to the standard deviation of the Q345 steel is 1.018 , and the coefficient of variation (defined as $\left.\sigma_{z} / \mu_{z}\right)$ is 0.067 .

During the course of seismic reliability analysis, the input and output variables must be defined. Based on the above analyses, the maximum stress effect of each critical section of the quayside container crane is defined as output variables. The mechanical properties of materials (elastic modulus, density and yield strength), the gravity and the ground acceleration are defined as input variables, which are shown in Tables 5 and 6 .

Table 5 Distribution parameters of the structure resisting force and the constant loading

\begin{tabular}{llcc}
\hline Parameter & Distribution type & Mean & $\begin{array}{c}\text { Standard devia- } \\
\text { tion }\end{array}$ \\
\hline$E / \mathrm{GPa}$ & Normal & 210 & 14.1 \\
$\rho /\left(\mathrm{kg} \cdot 10^{-3}\right)$ & Normal & 7850 & 52.595 \\
$S / \mathrm{MPa}$ & Lognormal & 345 & 23.1 \\
$G /\left(\mathrm{m} \cdot \mathrm{s}^{-2}\right)$ & Normal & $1.55 \times 10^{7}$ & $1.04 \times 10^{6}$ \\
\hline
\end{tabular}

Note: $E, \rho, S$, and $G$ denote elastic modulus, density, yield strength, and gravity, respectively. 
Table 6 Distribution parameters of the ground accelerations

\begin{tabular}{|c|c|c|c|c|c|c|c|c|c|}
\hline \multirow{2}{*}{$\begin{array}{c}\text { Ground } \\
\text { acceleration }\end{array}$} & \multicolumn{3}{|c|}{ EL Centro seismic wave } & \multicolumn{3}{|c|}{ Taft seismic wave } & \multicolumn{3}{|c|}{ SHW2 seismic wave } \\
\hline & Mean & $\begin{array}{l}\text { Standard } \\
\text { deviation }\end{array}$ & $\begin{array}{l}\text { Distribution } \\
\text { type }\end{array}$ & Mean & $\begin{array}{l}\text { Standard } \\
\text { deviation }\end{array}$ & $\begin{array}{l}\text { Distribution } \\
\text { type }\end{array}$ & Mean & $\begin{array}{l}\text { Standard } \\
\text { deviation }\end{array}$ & $\begin{array}{c}\text { Distribution } \\
\text { type }\end{array}$ \\
\hline AHX (longitudinal) & -0.14570 & 1.03409 & Normal & -0.04980 & 0.76229 & Normal & -0.03708 & 0.543157 & Normal \\
\hline AHY (lateral) & -0.12385 & 0.87898 & Normal & -0.04233 & 0.64795 & Normal & -0.03152 & 0.46168 & Normal \\
\hline AHZ (vertical) & -0.09471 & 0.67216 & Normal & -0.03237 & 0.49549 & Normal & -0.02410 & 0.35305 & Normal \\
\hline
\end{tabular}

\subsection{Reliability results}

Monte-Carlo method (referred as random sampling method or statistical test method) belongs to a branch of computational mathematics. Based on a probabilistic model, in accordance with the process described in this model and through simulation results, the approximate solution is obtained. There are three main steps in Monte Carlo method: constructing or describing the probability of the process, sampling from a known probability distribution, and establishing variety of the estimators.

Based on the Monte-Carlo method, the simulation times are 1000 . Under the excitation of the rare seismic intensity, the structure failure probability $p_{\mathrm{f}}$ and the reliability index $\beta$ of the critical sections are shown in Table 7. It should be noted that Table 7 only shows the failure probabilities of the part of the main components.

It is obtained from Table 7 that: (1) the maximum failure probability of quayside container crane structure is located in the joint of the horizontal beams and the waterside legs under the rare seismic intensities of 7 and
8; (2) for reliability indexes $\beta$ of several main components negative value have appeared, and exists the failure possibility; (3) under rare seismic intensity of 8 , the reliability index $\beta$ of the joint of the horizontal beams and the waterside legs is $-\infty$. It is illuminated that the seismic responses of the components here are large enough to fall short of the seismic design requirements.

In the course of reliability analysis, probability sensitivity is a key parameter, whose analysis results could provide the rank-order for the importance of the random variables. Figure 9 clearly shows the rank-order correlation sensitivity of the failure probability (element 89) under rare seismic intensity. It can be obtained from Figure 9 that the seismic action (ground acceleration) has the largest effect on the structure reliability index, whereas the gravity and the yield strength of material rank the second and the third, respectively. As regards to the other parameters, we may ignore their effect on the structure.

Table $7 \quad$ Failure probability $p_{\mathrm{f}}$ and reliability index $\beta$

\begin{tabular}{|c|c|c|c|c|c|c|c|c|c|c|c|}
\hline \multirow{3}{*}{ Seismic waves } & \multirow{3}{*}{$P_{\mathrm{f}}$ and $\beta$} & \multicolumn{10}{|c|}{ Key elements of the critical sections } \\
\hline & & \multicolumn{5}{|c|}{ Rare seismic intensity 7} & \multicolumn{5}{|c|}{ Rare seismic intensity 8} \\
\hline & & 878 & 744 & 1 & 89 & 1391 & 878 & 744 & 1 & 89 & 1391 \\
\hline \multirow[t]{2}{*}{ El Centro } & $P_{\mathrm{f}} / 10^{4}$ & 12.550 & 2578 & 5625 & 5925 & 3935 & 30.150 & 4563 & 9630 & & 6778 \\
\hline & $B$ & 3.000 & 0.650 & -0.156 & -0.235 & 0.271 & 2.742 & 0.109 & -1.788 & $-\infty$ & -0.459 \\
\hline \multirow[t]{2}{*}{ Taft } & $P_{\mathrm{f}} / 10^{4}$ & 69.560 & 3568 & 4854 & 5028 & 3569 & 148.900 & 6538 & 8569 & & 6023 \\
\hline & $B$ & 2.435 & 0.378 & 0.038 & -0.008 & 0.364 & 2.173 & -0.358 & -1.068 & $-\infty$ & -0.359 \\
\hline \multirow[t]{2}{*}{ SHW2 } & $P_{\mathrm{f}} / 10^{4}$ & 78.58 & 3933 & 5862 & 6537 & 3688 & 165.30 & 6726 & 9952 & & 7266 \\
\hline & $\beta$ & 2.415 & 0.371 & 0.217 & -0.396 & 0.336 & 2.131 & -0.445 & -2.590 & $-\infty$ & -0.605 \\
\hline
\end{tabular}
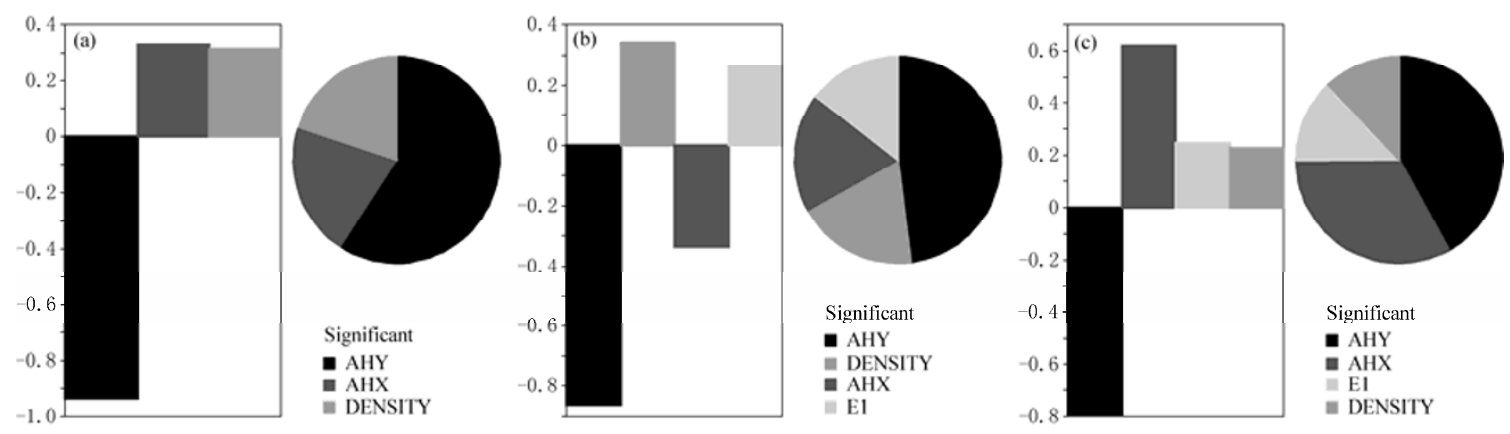

Figure 9 Rank-order correlation sensitivities of the element 89 under three groups of rare seismic excitations. (a) El Centro seismic wave; (b) Taft seismic wave; (c) SHW2 seismic wave. 
In general, the randomness of seismic action (ground acceleration) plays a decisive role in the structure seismic reliability. In conclusion, the overall structure of the quayside container crane is unstable under the excitation of rare seismic intensity, which is needed to be reinforced.

\section{Discussion and conclusions}

In this paper, an ideal elastic-plastic mechanical model of quayside container crane is presented by using the ANSYS codes, and the elastic-plastic time history analysis under rare seismic intensity is analyzed by taking advantage of El Centro, Taft and SHW2 seismic waves. On the basis of above analysis, the seismic reliability of the quayside container crane is estimated with MonteCarlo simulation. According to the analysis results, we could observe the seismic response and the seismic performance of the structure after entering into the plastic deformation.

The results show that, under the excitation of rare seismic intensity, the maximum stress is located in the joint of horizontal beams and waterside legs. Meanwhile, the existence positions of the maximum displacement are nearby the back-end of girder and the front-end of boom.

Under SHW2 excitation of the rare seismic intensity of 8 , the deformations of the back-end of the girder are very large, which obviously exceed stiffness requirements (sag-span ratio 1/750). Strong earthquake can make geometric nonlinearity of structure enhanced, leading to large deformation.

Under rare seismic intensity of 7 , the maximum stress value of each component of the quayside container crane is at low level, and within its elastic stage, without yielding. Nevertheless, under El Centro and SHW2 excitations of rare seismic intensity of 8 , the stress in the joint of the horizontal beams and the waterside legs is beyond the limited stress $345 \mathrm{MPa}$, and would produce plastic deformation there.

The maximum failure probability of the quayside container crane structure is located in the joint of horizontal beams and waterside legs under the excitation of the rare seismic intensities of 7 and 8 . The reliability indexes $\beta$ of the several main components is negative, indicating there exists failure possibility. Under the excitation of the rare seismic intensity of 8 , the reliability index $\beta$ of the joint of horizontal beams and waterside legs is $-\infty$. It is illuminated that the seismic response of the components here are large enough to fall short of the seismic design requirements.

In conclusion, there is no need to consider the influence of the material plasticity under three groups of seismic waves of the rare seismic intensity of 7 . However, under the rare seismic intensity of 8 , the seismic response of quayside container crane is large enough to induce plastic deformation. Therefore, the whole structure must be seismically reinforced.

Acknowledgements The study was supported by National High Technology Research and Development Program 863 Plan (No. 2009AA043000).

\section{References}

Jin Y L, Wu T X and Li Z G (2009). The anti-seismic performance analysis of quayside container crane based on limited state method. Journal of Vibration and Shock 28(12): 172-177, 187 (in Chinese with English abstract).

Lü X L, Zhu J J and Liu J (2005). Simplified elastic-plastic time history analysis with test verification of the structure of Shanghai World Financial Center. Journal of Earthquake Engineering and Engineering Vibration 25(2): 34-42 (in Chinese with English abstract).

Ministry of Construction of the People's Republic of China (2003). Code for Design of Steel Structure GB 50017-2003. China Planning Press, Beijing, 128-130 (in Chinese).

Ou J P, Duan Y B and Liu H Y (1994). Structural random earthquake action and its statistical parameters. Journal of Harbin University of Civil Engineering and Architecture 27(5): 1-10 (in Chinese with English abstract).

Ren J C (2007). Seismic Resistance Analysis and Design Method Study on Large-span Spatial Cable Stay Structures. Tongji University Press, Shanghai, 30-55 (in Chinese).

Wang T L (2007). Seismic Response Analysis and Vibration Mitigation Research for Long Span Cable-Stayed Bridges. Tongji University Press, Shanghai, 25-50 (in Chinese).

Wang Y Q (2006). Experimental Research on Mechanical Behaviors of Structural Steel 16Mn at Elevated Temperatures. Xi'an University of Science and Technology Press, Xi'an, 15-21 (in Chinese).

Wu X H, Yuan Z J and Lü X L (2008). Elastic-plastic time history analysis of T2 building of Shanghai Pudong International Airport. Journal of Earthquake Engineering and Engineering Vibration 28(4): 70-75 (in Chinese with English abstract).

Zhu J J and Lü X L (2006). Elastic-plastic time-history analysis of Shanghai World Financial Center Building. Journal of Natural Disasters 15(2): 49-56 (in Chinese with English abstract). 